\title{
Innovation and Development of Real Estate under Internet+ Environment
}

\author{
LI ZHAO YUN
}

\author{
Guangzhou Vocational College of Technology \& Business, Guangzhou, Guangdong, China \\ water1188@126.com
}

Keywords: internet+; real estate; innovation

\begin{abstract}
The real estate industry is related to our national economy and people's lives while it also affects the prosperity and development of our economy. Currently, under the impetus of the internet and informational industry, development of real estate also has gradually undergone great changes to high-quality and high-level direction. Development of the internet is both an opportunity and challenge for real estate. Thus, in order to promote economy of our country, enterprises of real estate need to grasp advantages of internet economy, respond actively to the reform as well as development under internet+ environment, and maintain stable and healthy development.

Under the rapid development of informational and network technology, internet has changed the original appearance of people's economic life and has brought more convenience to people's life in recent years as the driving force behind innovation and development of the economic ability. At present, China has entered the internet+ environment, and all walks of life are looking forward to promotion of their own business by using it. The real estate development relating to people' economy and livelihood also need to grasp this opportunity, integrate its own network resources, form unique competitive advantages, and promote their competitiveness. This study mainly focused on the strategies of innovation and development of real estate under the internet + environment.
\end{abstract}

\section{Generalization of the "Internet+" Model}

"Internet+" is a development model of "internet+ various traditional industries". It is also a development model of new forms and formats of internet development under the internet form evolution and new situation of economic and social development. "Internet+" is a practical innovation of internet thinking which has greatly promoted the development of social productivity and provided wide development platform of internet. The idea of "internet+" was first given on the Fifth Mobile Internet Expo, and then the Chairman of Tencent Ma encouraged industrial innovation of enterprises, realized cross-border integration, as well as promoting economy and social development of our country on March 2015. After that, various industries and sectors have joined the development of "Internet+" and lunched strategic cooperation which includes two aspects: the first one is traditional industries use internet technologies and platforms' resources to realize self reform and development; the second one is to cultivate a innovative development form of new products through different cross-border integration from different industries driven by internet technologies and thought. The development of "Internet+" has ability to promote restructuring and development of industrial economy, also provide wider space for development and innovation.

\section{Analysis about the Necessity of Innovative Development of Real Estate Enterprises under "Internet+" Model}

\subsection{It is necessary to apply "Internet+" in new industry format of real estate}

Real estate can realize variation development by using new innovative commercial model under "Internet+" model, because it involves various departments. Additionally, enterprises of real estate can effectively unlock the capital for enterprises 'development to provide adequate financial support by financing under the "Internet+" model. Cross-border integration supplied by "Internet+" inspired second entrepreneurs, and bring development power of real estate into a higher level by grasping the market faster, more accurate and concentrated. 


\subsection{Requirements of macroeconomic}

With the development of global and informational economic model, the development models of mobile internet, intelligent terminals and other huge data have contributed to the transaction of consuming internet into industrial internet. In the influence of economic crisis, the development of real estate has to take advantage of modern informational technology to realize technological innovation and promote stable growth of real estate economy. At present, internet industry and mobile internet are developing rapidly, and the application as well as development of informational technology has become a new developmental tendency of society. The development of mobile internet traffic made the new grow-up industries face with the developmental needs of traditional enterprises in the fields of new technology and commercial format, which also bring good commercial opportunity for traditional enterprises. As one of the traditional enterprises, real estate has to grasp this developmental opportunity and realize transformation and leap-forward development through enlarging market using internet technology. The real estate began to change the traditional way of producing and organization through cross-border cooperation and resource integration. It also brought the real estate industry into a higher level by improving the management and service level though using innovative products and service of internet technology.

2.3 It is the inevitable choice for real estate to adapt market changes

Development of China's real estate industry has experienced three changes: the first is variety of rental demand and supply relationship; the second is change of demanded levels and living concept; the third is transformation of developmental connotation. Anyway, real estate development and change are inseparable from the process of change about people's needs, and actually it is also a process of transformation from traditional needs into modern ones. With the improvement of people's living standards, the residential needs have changed greatly into direction of personalization and diversification. The consumers should have known about the surrounding environment, education, culture and residential condition before purchase of houses because of complex supply and demand in modern market. The advantage of internet under huge data is to meet the various philosophy needs. Main role of internet is to integrate useful information, change way of getting access to information and communication, and provide information to consumers pertinently. At the same time, enterprises of real estate could use information integrated to make products' service suitable for selling, to provide one-stop butler service for consumers, and improve life quality of home owners.

\section{Main Problems of Real Estate Industry under "Internet+" Environment}

\subsection{High costs and small profits of traditional operating model}

In recent years, with many problems like inflation, increasing prices level, rising labor costs, and rising wages have squeezed profits sources of enterprises; followed by prices volatility of energy and raw materials, it caused the enterprises lose competitive advantages of low costs and high profits. When the real estate enterprises have difficulties in transformation of the rising investment costs, they would be facing with declining profits and serious negative tax, especially for some small and medium enterprises. These factors have influenced the further development of traditional real estate enterprises. In order to occupy a place in the market, enterprises must carry out strategic restructuring and development.

\subsection{Low core competitiveness of enterprises}

Improvement of core competitiveness of real estate enterprises is the key step and fundamental task to promote the development of enterprises. Currently, lack of core competitiveness is the main problem of small and medium real estate enterprises during development. These facts lead to difficulties of to competing with other competitors, or even have been beaten, especially for those small and medium real estate enterprises. Additionally, there is huge gap between them and large enterprises, which cause they don't have ability to fight back. Other main reasons caused low competitiveness of enterprises are lack of innovative ability, poor strategic awareness, low management capacity, and unclear brand awareness. While the enterprises have financing problems because of low developmental ability, it is not good for further development. Meanwhile, the real 
estate enterprises haven't brought the talent strategy into the overall operating strategy during this age of knowledge economy, and this is another main cause of lack competitiveness.

2.3 Single financing channels and high assets liability ratio

In recent years, economic competition is getting more intense and some of these enterprises are small and medium ones. These enterprises have serous problems with financing because of their small economic power to handle the rapid change of market. From a practical point of view of development, the capital of real estate enterprises generally came from self-financing, domestic loans and other methods while the self-financing accounted for about $50 \%$. From the data, we can see that the real estate industry has relatively small ability to use foreign capital, and it is difficult to meet their own development though relying solely on government loans and bank financing. This single financing method is not conducive to the further development and financing of the real estate, and it also limited expansion of the enterprises. In addition, strength of real estate development is not very high, so there is a big difficulty in financing. Although there are many ways of nongovernmental financing under the rapid development of national economy, there still have problems with market management and supervision. Thus financing from real estate enterprises are mainly from bank loans which has limited the flexible development of enterprises. As can be seen from Table 1, investment of the real estate business development is mainly from domestic loans and self-financing while the utilization of external force is relatively low; Bank loans accounted for 20\% $-30 \%, 60 \%$ investment of real estate companies came from bank loans, and direct financing from capital market is less than $10 \%$ of the total financing.

Table1: Guangdong 2012-2015 developmental investment funds of small and medium real estate enterprises

\begin{tabular}{|l|l|l|l|l|l|}
\hline Year & $\begin{array}{l}\text { Total } \\
\text { financing }\end{array}$ & Bank loans & $\begin{array}{l}\text { Foreign } \\
\text { capital }\end{array}$ & Self-financing & Other funds \\
\hline \multirow{2}{*}{2012} & 623 & $96(93)$ & 5 & $262(119)$ & $238(48)$ \\
\cline { 2 - 6 } & 100 & $16.1 \%(15.5 \%)$ & $0.83 \%$ & $43.6 \%(19.8 \%)$ & $39.6 \%(7.9 \%)$ \\
\hline \multirow{2}{*}{2013} & 800 & $125(116)$ & 2 & $408(170)$ & $263(65)$ \\
\cline { 2 - 6 } & 100 & $15.7 \%(14.5 \%)$ & $0.25 \%$ & $51.1 \%(21.3)$ & $32.9 \%(8.2 \%)$ \\
\hline \multirow{2}{*}{2014} & 1500 & $217(200)$ & 5 & $585(268)$ & $511(135)$ \\
\cline { 2 - 6 } & 100 & $16.5 \%(15.2 \%)$ & $0.38 \%$ & $44.4 \%(20.8 \%)$ & $38.7 \%(10.2 \%)$ \\
\hline \multirow{2}{*}{2015} & 1700 & $215(203)$ & 6 & $642(292)$ & $820(236)$ \\
\cline { 2 - 6 } & 100 & $12.8 \%(12.1 \%)$ & $0.36 \%$ & $38.1 \%(17.3 \%)$ & $48.7 \%(14.1 \%)$ \\
\hline
\end{tabular}

2.4 Imbalance of demanded structure in real estate industry

In recent years, urban housing stocks of our country have reached 240 million square meters and residential constructions have reached 5.9 million because of faster urbanization process according to the relevant data. Analysis from the whole development, urban housing problems of our country have been relieved, but there are till some troubles with imbalanced distribution during different people, and the current existing stocks of housing in real estate market are not matching with Aspects of size, price, and the potential market demand. Real estate development must obtain valid market information and promote accurate delivery market. In addition, real estate development has gradually shifted from sellers' market into buyers' market under the change of market. In this development environment, real estate development must also be active and innovative in marketing strategies, and expand marketing channels to promote further development of real estate industry. 


\subsection{Quality of staff is low}

Since the new century, the key point to competition in the market depends on the talent competition, and we can say that talent competition is the main aspect of increasing the core competitiveness of enterprises. The two disadvantages of development including land and financial resources are difficult to fight with huge enterprises, so the small and medium enterprises have to consider improvement local development advantages from talents' aspect in order to counterattack huge ones. Talents reservation is important also because there are large amount of real estate enterprises, and they need more staff who master modern informational technology like marketing, sales, and after-sales service. Because of their own developmental limits, the real estate enterprises are difficult to attract high-quality talents and the talents' application of modern information technology is inadequate which cause series of problems: there are fewer professional staff in the fields like finance, construction, real estate sales and other aspects; whole quality performance of enterprises is rather poor; it is difficult to form the core team values and ideas which easily lead to a lack of manpower support enterprise development, and not conductive to stable as well as healthy development.

\section{New Developmental Measures of Real Estate Industry under "Internet+" Environment}

Chinese real estate industry has made good achievements in development, the traditional mode of operation can not adapt to the real estate development of modern society with the progress of science and technology and the development of market economy. So we must actively take advantage of new science and technology to realize innovative development in industrial structure and promote better development in our country.

4.1 Implementation of "Internet+ industrial integration" development in real estate

In the ever-changing information in internet environment, and the connection is an important countermeasure for development in this environment, which means the real estate industry needs to realize the connection between industries and people in order to form extension and expansive development. In the network environment, the chains of real estate industry must be linked together and closely develop. In recent years, although the level of service in real estate has increased, the added value and increasing production value of internet technology are still have huge space of development. Real estate is difficult to move, but it can be integrated with financial, cultural, commercial, educational and medical aspects after access to the internet. After the real estate becomes movable economy, it can realize the promotion of lifetime value of residential real estate and quality of life. Implementation of the "Internet + industrial integration" has made contribution to connection among real estate, design, development, production, financing and other aspects linked to other industries. In the development of real estate, it can be real estate+ internet or internet+ real estate. For examples, Green Group uses "internet+ big finance” to invest construction of subway industry, Country Garden uses "internet+ hotel management" to improve service professionalization.

4.2 Implementation "internet+ financing” in development

At present, the high cost of financing is one of the major limiting factors. And implementation of the "Internet + financing" in the Internet environment as an innovational financing way can effectively reduce the cost of financing for development: use "Internet+" to seek diversified developmental financing channels, not just rely on bond financing and trust financing, but also actively use equity financing, securities financing, internet technology to actively expand financing channels; take advantage of the "Internet +" to develop a global financing plan to actively explore financing ways with low costs in some negative interest rates or low interest rates countries. In recent years, globalization of real estate investment projects in the external carotid gradually increased, and the real estate industry can use the "Internet +" actively to expand financing channels for development as well as select optimal financing mode which can provide more finance support in the development of our country. Xiamen has launched cross-border RMB loan business that can reduce difficulties of cross-border real estate financing and enrich real estate financing channels. 
4.3 Implementation of "Internet+ innovative service and technology" in development

The development of real estate can not be the same as the traditional mode of operation in the "Internet +" developmental environment, we need to launch technological innovation and service development to actively expand the real estate marketing and innovation. In the Internet + innovative services and technological development, after getting full knowledge of the urbanization of reform and development as well as functional urban construction and spatial layout of cities, the enterprises make full use of the Internet + technology to search the most advanced design concept and planning worldwide, actively promote BIM information. Learning advanced technology and service experience from successful countries especially in using of foreign constructive skills has greatly improved our real estate design effect, promote energy-saving efficiency of the buildings, effectively improve China's real estate design concept of service innovation, and improve customers' satisfaction. Construction units using the Internet + technology can choose the most advanced construction equipment worldwide to effectively shorten the construction period, improve construction quality and reduce the cost of real estate construction. Strengthening the international communication in the design, construction, marketing and other aspects of real estate industry also lead to cross-technology professional development and constructive quality improvement. 4.4 Implementation of "Internet + marketing"

At present, China's economy is mainly characterized by the development of consumption upgrade, and housing consumption occupy an important proportion in the consuming market while the Internet for marketing purposes is to expand consuming groups. Development of "Internet + marketing" model can simplify and improve real estate management level. Convenient information can provide functional access to looking up useful things, and promote development of housing rental market, and increase new house trading volume. Secondly, the "Internet + Marketing" make housing more intuitive, open, and able to provide more transparent price information for consumers which can realize interaction and price negotiation from point to point. On the current form of real estate development perspective, "Internet + Marketing" has a better effect in the development of urban consumers' base.

4.5 Implementation of the "Internet + Training"

For now, the problem of low quality of real estate practitioners can be solved with "Internet+ training" effectively. Firstly, employees learn to use the internet for product sales to improve the level of information. At the same time, using the internet regularly to carry out network training and provide more comprehensive as well as professional platform which can realize improvement of staff quality. Analysis from this aspect, we can see that using "Internet+ training" model can effectively improve comprehensive quality of employees, their ability to use informational technology and promote the real estate sales by using network technology.

\section{Conclusion}

In the information of network, the real estate industry also has to implement the reform and development business model, actively carry out innovation and development, abandon the traditional business model, and promote the development of modern real estate. "Internet +" application makes real estate get a better understanding of the needs of the target customer groups in order to develop products and service more suitable for consumers. Further use of the "Internet +" in real estate financing, industry convergence, innovative services technology, etc can effectively improve the level of real estate development business, promote better development of real estate industry from different aspects, and promote the sustainable development of real estate industry in society.

\section{References}

[1] Qiu Xiang, Innovation and development of real estate industry under the background of a low-carbon economy [J] Suppliers, 2015 (21): 261-261. 
[2] Liu Zhifeng, Real Estate Industry to Do Good "Math" [J] Urban Development, 2015, (2): 1.

[3] Liu Zhifeng, Real Estate Industry to Do Good "Math" [J] Zhongzhou Construction, 2015, (6): 64-67.

[4] Yan Wenzhen, Seize the Opportunities of Innovation and Development - the "Internet Era Property Management Revolution Forum" held in Jinan [J] China Property Management, 2015, (1): 7-8.

[5] Liu Zhifeng, Using the Internet Means Thinking and Innovative in Real Estate Development [J] Zhongzhou construction, 2015, (22): 67-68.

[6] Zhangyong Yue, New Development and Deepen the Reform of Land System in Real Estate [J] Central China Normal University (Humanities and Social Sciences), 2009,48 (4): 47-51.

[7] Wang Ren, Innovation and Promote the Transformation and Leaping Development in the City Real Estate [J] Information Development and Economy, 2011,21 (32): 150-153.

[8] Liu Zhifeng, Real Estate Industry Transformation and Upgrading and Innovation and Development [J] Urban Development, 2013, (6): 45-49. 